\title{
Investigation of latest techniques in carbon sequestration with emphasis on geological sequestration and its effects
}

\begin{abstract}
In the pursuit of development, man has polluted and exploited many resources provided by mother nature. In these pollutions, $\mathrm{CO}_{2}$ pollution has become the most concerning contemporary and sought after problem in the current scenario. Observations indicate that the Carbon concentration levels have exceeded beyond the threshold limits. Among the solutions available currently, Carbon-Capture and Storage (CCS) or Carbon Sequestration (CS) is the best solution considering the cost and efficiency of carbon removal from the atmosphere. In the available Carbon sequestration methods, a geological sequestration is a viable option for long-term sustainable storage of $\mathrm{CO}_{2}$. This article focusses on latest technologies developed with respect to Geological Sequestration and also on the carbon capture techniques, site selection for Geological sequestration, transport as well as uncertainties and difficulties in the modeling of the involved process. The main objective is to stress the need for these techniques and motivate fellow researchers in this essential and emerging field.
\end{abstract}

Keywords: greenhouse gas, carbon capture and storage (CCS), geological storage, carbon Sequestration, $\mathrm{CO}_{2}$ mitigation
Volume 4 Issue I - 2019

\author{
Boindala Sriman Pankaj,' Jagadeesh Anmala ${ }^{2}$ \\ 'Graduate Student, Birla Institute of Technology \& Science, India \\ ${ }^{2}$ Associate Professor, Department of Civil Engineering, Birla \\ Institute of Technology \& Science, India
}

\begin{abstract}
Correspondence: Prof. Jagadeesh Anmala, Associate Professor, Department of Civil Engineering, Birla Institute of Technology \& Science, Pilani, Hyderabad Campus, India,

Email jagadeesh@hyderabad.bits-pilani.ac.in
\end{abstract}

Received: June 28, 2018 | Published: January 30, 2019

\section{Introduction}

Though there has been an increase in the level of Greenhouse Gasses (GHG) from the advent of industrialization, which occurred in the late $17^{\text {th }}$ century, there has been a rapid growth of the release of these gases from the early $20^{\text {th }}$ century. These changes have adversely affected the global climatic conditions. Various Global Climatic models (GCM's) predict that the increase in the concentration of these gases will be much more in the near future because more and more countries are getting developed/industrialized. These emissions are mainly due to the consumption of fossil fuels for energy. Though there are many alternatives suggested for energy production, scientists say that fossil fuels will be the main source for the foreseeable future (Park et al. 2004). The main component of these GHGs, which contribute to the increase in the global climatic temperature, is Carbon- dioxide. Carbon sequestration is one of the major methods to mitigate the effects of fossil fuel emissions.

\section{What is carbon sequestration?}

Carbon sequestration is a process in which the atmospheric carbon-di-oxide, carbon monoxide, and other forms of carbon, which are linked to global warming and air pollution are captured and stored in carbon sinks for long-term storage. This occurs naturally through many physical, biological and chemical processes. But these natural processes take a huge amount of time in their cycles and cannot compete with the current carbon generation. Therefore, new techniques are developed which artificially capture the carbon-related gases released by industries and store in various carbon sinks like reservoirs, saline aquifers, aging oil fields, oceans, etc.

\section{Physical processes}

\section{Biomass sequestration}

This is nothing but reforestation. The trees and plants take carbon- dioxide from the atmosphere and convert them into biomass as they grow. So, the carbon can be stored as biomass in trees/plants until they decompose or are burnt. The problem with this is that the carbon is stored only for a limited amount of time, roughly say for about 80 to 90 years, and therefore, this cannot be a viable solution for the capture of all the carbon which we release into the atmosphere.

For solving this problem, scientists have come up with various technologies to prevent the carbon escape like bioenergy with carbon capture and storage (BECCS), biochar burial, and biomass burial. Bioenergy with carbon capture is a method in which the produced biomass by the plants is sent to industries to be used as a biofuel to generate bioenergy. The carbon dioxide released with this method is then captured and is stored into the geological formation where the carbon is stored for more than 10000 years with very less probability of escape. ${ }^{1}$ Biochar is nothing but a type of charcoal used as a soil amendment/soil conditioner prepared by thermal decomposition of the biomass without oxygen. Based on the temperature, the rate of heating and other physical conditions the amount of biomass converted to biochar can vary from $20 \%$ to $50 \%$. Other by-products can be used as biofuel.

\section{Ocean storage}

The pressures at the ocean bottom are large to contain $\mathrm{CO}_{2}$ in its liquid phase. ${ }^{2}$ At this location, it is easier to get stable and stationary pools of carbon-dioxide. The potential capacity of an ocean is very large and can hold more than a thousand billion tons of carbon dioxide. Ocean storage is not encouraged due to the impact of carbon dioxide on ocean life and its stability primarily.

\section{Sub-terrain storage}

Sub-terrain storage/geological sequestration means to store carbon-di-oxide in depths of the earth like in depleted gas reserves and other fossil fuel reservoirs, un-minable coal mines, etc. Once 
the $\mathrm{CO}_{2}$ is captured it is then subjected to high pressure until the gas enters a supercritical state. This liquefied gas is then pumped to the depths of the earth through pipes. It is believed that the pressure at those depths is sufficient to store the carbon-di-oxide for thousands of years in the liquid state. ${ }^{3}$

\section{Chemical processes}

\section{Mineral carbonation}

The mineral carbonation/mineral carbon sequestration is a method in which the captured carbon-dioxide reacts with mineral oxides like Magnesium Oxide and Calcium Oxide and form respective carbonates. This reaction occurs naturally and is also the reason for the weathering of rocks due to their exothermic nature. These can also happen with mineral silicates like magnesium and calcium silicates which produce Silicon-DI-Oxide along with their carbonates. This reaction is also exothermic but comparatively less in its intensity compared to the above reaction. These obtained carbonates can be stored in the earth as landfills. This method of sequestration is known to be permanent without any chances of leakage issues. The main problem with this method is the availability of raw materials and the extraction of these materials is of much concern.

\section{Chemical scrubbers}

Chemical scrubbers are natural or artificially made materials to capture $\mathrm{CO}_{2}$ and separate them from the other gaseous materials. These scrubbers are initially used in rebreather in a diving suit. The researchers are now investigating their use in carbon capture and storage. There are various kinds of scrubbers available in the market which are:

a. Amine scrubbers: Amine scrubbers have been known to man since 1930s and are used for carbon dioxide removal. When amines come in contact with acidic gasses like $\mathrm{CO}_{2}$ they convert $\mathrm{CO}_{2}$ to bicarbonate ion which can dissolve in the solution. The main advantage of these scrubbers is that they can release the carbon-di-oxide when the solution is heated which makes the amine solution reusable.

b. Zeolites and metal-organic frameworks (MOFs): Zeolites or MOFs can be used to bind carbon dioxide reversibly. MOFs can be specifically manufactured to adsorb only carbon dioxide. The problem with this method is that they utilize many minerals whose mining may lead to other climatic problems.

\section{Biological processes}

The biological processes can be classified into two categoriesterrestrial and aquatic. In these processes, the pace of natural carbon sequestration is increased by increasing the population of the photosynthetic organisms via artificial methods. The main problem with these is that the storage is not permanent and the problems caused by artificial indulging in the ecosystem may lead to other harmful consequences.

\section{Carbon capture technologies}

There are various stages in the carbon sequestration process out of which carbon capture is the most important and expensive stage. Almost 60 to $70 \%$ of the cost of CCS is utilized in carbon capture and the schematic diagrams of its processes could be found from Breeze. ${ }^{4}$ As of now most of the carbon capture techniques are available for stationary sources and very few techniques for remaining sources. These techniques are classified into various types as follows:

\section{Separation with solvents}

This process takes place in two stages, the first stage is the absorption of $\mathrm{CO}_{2}$ by a solution and the second stage is the desorption by pressure or temperature variation or by an electrical impulse. In general, the exhaust gases from the industries or other point sources will be at high temperatures. So, before absorption, first we need to cool down this exhaust to a nominal temperature (normally around $\leq 40-60^{\circ} \mathrm{C}$ ), then we allow the exhaust to pass through the absorbent chamber. In this stage, the carbon dioxide is absorbed and all the other gases which are inert to the solvent are released out. Then this solvent filled with $\mathrm{CO}_{2}$ is sent to the desorption chamber where the $\mathrm{CO}_{2}$ is separated through pressure or temperature variation or by an electrical impulse. After desorption, the solvent is again circulated for absorption and the carbon dioxide is then compressed for easy transport and storage (at pressures around $10-80 \mathrm{MPa}$ ).

\section{Separation by sorbents}

This is similar to the above process, but instead of solvents, we use sorbents like activated carbon, zeolites, aluminophosphates etc. The carbon dioxide is adsorbed and not absorbed, reducing the amount of energy in desorption, but in decreasing the efficiency compared to that of absorption. Though there is a reduction in efficiency, this kind of separation process is also widely used.

\section{Separation through selected membranes}

Another method for separation of carbon is through selective membranes. The type of gases it can separate is based on the material of the membrane and the quantity of gas that can be separated is dependent on the pressure change across the membrane. The membranes can either separate the gases or can absorb the desired $\mathrm{CO}_{2}$ gas.

\section{Separation with other technologies}

\section{Cryogenic distillation}

This process is a bit complicated compared to the other problems, but the yield of carbon dioxide, which we obtain, is high compared to the others mentioned above. In this process, the flue gas is subjected to a controlled, steady increase of pressure and a reduction in temperature is achieved to reach the triple point of the carbon dioxide $(216.6 \mathrm{~K}$ at $5.11 \mathrm{~atm} \mathrm{P}$ ) so that other gas will be in a gaseous phase where $\mathrm{CO}_{2}$ will be in the triple state and can be easily separated out. The problem with this is that the flue gas should be cleared from $\mathrm{H}_{2} \mathrm{O}$, NOx, SOx and $\mathrm{O}_{2}$ prior to the distillation process and this method is also costly and even energy intensive compared to other methods.

\section{Ionic Liquids}

Organic salts which are stable at room temperatures are called ionic liquids. Few of these salts are found to be highly affinitive towards carbon-di-oxide. With the discovery of 1-butyl-3-methylimidazolium hexafluorophosphate being able to dissolve carbon-dioxide in huge amounts up to 0.72 -mole fraction, ${ }^{5}$ the popularity of ionic liquids for carbon capture has increased. Another advantage of using ionic liquids is that though high amounts of carbon-di-oxide are being dissolved very least part of the liquid is in the $\mathrm{CO}_{2}$ phase which makes it ideal for separation. These make them highly potential capture materials for carbon capture.

\section{Enzyme-based system}

Carbon capture through enzyme is another latest technique, which tries to mimic the natural process of capturing carbon. Carbonic 
Anhydrase (CA) is an enzyme used to convert $\mathrm{CO}_{2}$ to bicarbonate ion $\left(\mathrm{HCO}_{3}^{-}\right)$. The hydration rates are as fast as $10^{4}$ to $10^{6}$ molecules of carbon-di-oxide per second for every molecule of CA (Nguyen and Codexis 2012; Yong et al. 2017). The rates can be controlled by controlling the $\mathrm{pH}$ of the medium. Though this is promising, the enzyme cost and loss of enzyme activity are reducing its popularity.

\section{Geological sequestration}

Geological sequestration is nothing but the subterranean storage explained in physical processes of the previous section.

\section{Principles and mechanisms of geological carbon sequestration}

\section{Geological sinks for carbon storage}

Carbon dioxide is a naturally generated gas, which is stable at normal atmospheric conditions. At $31^{\circ} \mathrm{C}$ and pressure more than 7.38MPa, carbon dioxide is found to be in the supercritical state. At such critical conditions, carbon-di-oxide fills the usable volume and has a 'liquid-like density' which changes depending on applied or surrounding pressure. Though the $\mathrm{CO}_{2}$ is soluble in water in general, it is immiscible in water in the supercritical state. In such conditions of temperature and pressure, $\mathrm{CO}_{2}$ forms a hydrated crystalline structure which is heavier than water. The $\mathrm{CO}_{2}$ also has a strong affinity to coal, which is greater than methane gas normally found in coal mines. These properties of $\mathrm{CO}_{2}$ help us in finding appropriate sinks for carbon storage.

\section{Storage in salt caverns}

Salt caverns have been a used as a storage site since 1940's for many fossil fuels. Use of these storage sites can provide a long-term solution, but the associated cost for the storage is quite high and the disposal of the resulting brine solution is also an environmental hazard.

\section{Oil displacement in reservoirs}

The property of $\mathrm{CO}_{2}$ to reduce the viscosity and capillary pressure of liquid fossil fuels and oils makes it a well-suited substance for enhanced oil recovery (EOR). ${ }^{3}$ EOR is a process in which the gas is pumped into the oil wells and the residual oil is then displaced due to the interaction of these gases with the oil. About $40 \%$ of the residual oil can be displaced with $\mathrm{CO}_{2}$ in the process of EOR. This method provides us with both the uses-EOR and sequestration. The main problem to use this for sequestration is that the $\mathrm{CO}_{2}$ storage is very less and the $\mathrm{CO}_{2}$ obtained from the capture is highly un-economical compared to natural production of $\mathrm{CO}_{2}{ }^{6}$

\section{$\mathrm{CO}_{2}$ sequestration in coal mines and the displacement of methane}

Carbon dioxide is injected into deep coal mines and mines which are uneconomical to mine $\mathrm{CO}_{2}$ back. By doing this, the injected carbon dioxide displaces the methane gas present in the mines due to its affinity towards coal being greater than methane. ${ }^{7}$ Though methane is also a greenhouse gas, the use of methane over coal is much effective as methane is a better fuel than coal which reduces the $\mathrm{CO}_{2}$ emissions. This can be an effective mid or long-term storage method.

\section{Storage in depleted hydrocarbon reservoirs}

Hydrocarbon reservoirs are better storage sites compared to the liquid fossil fuel reserves. The main advantage is the presence of existing trapping conditions, which will ensure the separation of injected carbon dioxide from reaching the surface. This advantage over other sites makes the sequestration much easier and economical.

\section{Storage in deep saline aquifers}

Beneath the earth's crust, there are many water storage strata called aquifers. Some of these aquifers contain high concentrations of salts making it unusable for consumption or agricultural use. The solubility of carbon dioxide increases with increase in salinity of the water. ${ }^{8}$ Because of this property of carbon dioxide, saline aquifers can be potential storage sinks for $\mathrm{CO}_{2}{ }^{9,10}$ Due to the deep location of these aquifers the existing pressure present is sufficient enough to reduce the density of carbon dioxide closer to the water which prevents it from escaping out. Though there might be the drift of these waters beneath the earth, the velocity of flow of water is in the order of $\mathrm{cm} /$ year. Deep saline aquifers have been proved to be the most potential carbon sequestration sites in all aspects from volume to cost, with almost zero environmental impact. ${ }^{7}$

\section{$\mathrm{CO}_{2}$ sequestration in geological media and its criteria}

There are different criteria in choosing a particular site for geological sequestration. These criteria can be classified into the following and should be considered in order of-geological, hydrodynamic and geothermal, hydrocarbon potential, and economic, political and societal criteria. ${ }^{8}$

Geological criteria: The sites which are technically stable and are not subjected to frequent quakes or volcanoes are considered to be the best sites.

Geothermal criteria: The researchers found out that the temperature gradient is $25^{\circ} \mathrm{C} / \mathrm{km}$ and there will be an increase of $1 \mathrm{Mpa}$ pressure with the depth of $100 \mathrm{~m}$ as we go below the ground. ${ }^{11}$ This assumption is not always true for all the sites. We need to investigate other geological features like the presence of magma.

Hydrodynamic criteria: We also need to check the presence of water regimes in the storage sites before the injection of $\mathrm{CO}_{2}$ because some coal sites might contain flowable groundwater which might leak the carbon dioxide.

\section{Trapping mechanisms in geological sequestration}

As mentioned above the carbon-di-oxide is mostly injected in a supercritical state because of its density which is more than in its normal state. ${ }^{3}$ Depending on the available reservoir conditions, $\mathrm{CO}_{2}$ can be stored in supercritical, liquid or gaseous states. Mostly $\mathrm{CO}_{2}$ is allowed to freely move laterally and vertically inside the reservoir. ${ }^{12}$ Trapping of $\mathrm{CO}_{2}$ inside the geological formation as a residual gas occurs when the formation water invades or comes in contact with the $\mathrm{CO}_{2}$ plume. ${ }^{10}$ Four kinds of trapping mechanisms occur inside the reservoir but they do not occur at the same time. All these mechanisms are briefly explained below.

\section{Hydrodynamic traping}

Structural or hydrodynamic trapping refers to the $\mathrm{CO}_{2}$ which is trapped in a gaseous or supercritical state under a caprock with low permeability. When the $\mathrm{CO}_{2}$ is injected into the formation, due to its less density compared to formation fluid it rises up towards the caprock due to buoyancy. Due to the high capillary pressure of caprock compared to the hydrodynamic force of $\mathrm{CO}_{2}$, the injected $\mathrm{CO}_{2}$ resides or is trapped inside the reservoir. This is one of the most important 
trapping mechanisms as it is a preliminary trapping condition where it ensures that $\mathrm{CO}_{2}$ is stored until other trapping mechanisms come into action. ${ }^{13}$

The efficiency of this kind of trapping mechanisms of a reservoir/ formation can be evaluated by examining the sedimentary basins, the locations of strata having high and low permeability as those control the nature of the flow of fluids in that reservoir. ${ }^{12}$ There are many kinds of structural traps which can be used as physical traps for carbon storage among those commonly we can see anticlinal folds and sealed fault blocks. The storage capacity of these reservoirs is determined by the volume of pore spaces. $\mathrm{CO}_{2}$ can be injected until it reaches a point where the pressure of $\mathrm{CO}_{2}$ is more than the capillary entry pressure.

\section{Residual trapping}

Residual or Capillary trapping can be observed mostly when we use saline aquifers or any other formation containing a fluid. When the Carbon dioxide is injected into the formation it displaces the existing fluid in the capillary pores, when the injection is stopped the fluid again tries to occupy the pore spaces. While doing this only the top layers of the pores are replaced trapping most of the Carbon dioxide in its bottom layers. Fluid previously existing in the reservoir acts as a seal in this kind of trapping mechanism.

\section{Solubility trapping}

Solubility trapping occurs after the above-mentioned trappings. It is a trapping mechanism wherein $\mathrm{CO}_{2}$ dissolves in the formation liquid. In general, the formation liquid is a brine solution. When the $\mathrm{CO}_{2}$ is injected into the formation it spreads completely over the surface of the formation liquid. As soon as the $\mathrm{CO}_{2}$ touches the formation liquid, mass transfer takes place between the formation liquid and $\mathrm{CO}_{2}$ until it reaches equilibrium. The rate of dissolution of $\mathrm{CO}_{2}$ in water increases with increase in salinity. This process is very slow compared to the above trapping mechanisms as the molecular transfer rate coefficient is too small. It is assumed that to completely dissolve the $\mathrm{CO}_{2}$ in the brine liquid in the formation, it takes about 1000 years. $^{14-16}$

In the dissolution of $\mathrm{CO}_{2}$, a process named DDC (dissolutiondiffusion-convection) occurs. In this process, when the $\mathrm{CO}_{2}$ dissolves in the top layer of the brine solution, it becomes denser compared to its original state. This makes the top layer to come down and the bottom layer to go up. This process continues to increase the formation's storage capacity.

\section{Mineral trapping}

Mineral trapping implies the permanent containment of $\mathrm{CO}_{2}$ in stable forms when reacted with the minerals and other organic matter present in the formations. This trapping mechanism takes a very long time to initiate compared to the above-mentioned mechanisms. After the dissolution of $\mathrm{CO}_{2}$ into the formation liquid, the formation minerals undergo various chemical reactions. Some of these reactions are favorable to us due to the formation of carbonates which is a permanent storage form for $\mathrm{CO}_{2}$.

\section{Geological sequestration of $\mathrm{CO} 2$ and its transport}

\section{A. Modelling transport of $\mathrm{CO}_{2}$ for GCS (geological carbon sequestration)}

The location of carbon capture and storage might not be always in the same location. Sometimes the location of both of these sites might be far from each other. For this purpose, transportation of carbon or related gases also arises in CSS processes. In general, onshore transportation of $\mathrm{CO}_{2}$ is done by using pipes or tankers while offshore transport is done by using ships and sometimes by pipes.

\section{Pipe modeling of transport}

In general, $\mathrm{CO}_{2}$ can be transported in solid, liquid or gaseous state. But transporting $\mathrm{CO}_{2}$ in the supercritical state (at a pressure of $7.36 \mathrm{Mpa}$ and temperature of $30^{\circ} \mathrm{C}$ ) is most economical. $\mathrm{As} \mathrm{CO}_{2}$ in this phase has low viscosity and high density, very small diameter pipes can be used. Maintaining constant high pressure in a pipe is reasonably possible, but maintaining a constant temperature throughout is very difficult. The temperature of the material that is being transported depends on the surrounding temperature. It is possible that the surrounding temperature may vary to some extent. The pipes are usually buried underground, and in the soil, the temperature does not vary much. We need to take care of two-phase flow of $\mathrm{CO}_{2}$ in pipes because that might damage the pumps or other equipment used while transporting through pipes.

\section{Design of pipes systems}

The pipe design for $\mathrm{CO}_{2}$ is almost the same as the pipe design used for transportation of various other fossil fuels. One of the important conditions to be maintained is that the pressure should not drop below the critical pressure $(7.36 \mathrm{MPa})$ and the other conditions should be such that there is no two-phase transportation through the pipes. There are various components in the design of pipes for transport, which are as follows:

a) Amount of $\mathrm{CO}_{2}$ to be transported in the supercritical state determines the design of pipe

b) Design of compressors, pumps and other machines used to maintain $\mathrm{CO}_{2}$ in single-phase dense state

c) Design of valves and other components for controlling, operating and monitoring the transport. ${ }^{17}$

Pipe design: The internal diameter (d) of the pipe is calculated assuming a uniform gas velocity throughout the pipe. A standard velocity equation is used to compute this parameter.

$$
d=\sqrt{\frac{4 Q}{\pi U}}
$$

Where $\mathrm{d}$ is the internal diameter of the pipe, $Q$ is the flow rate, $U$ is the uniform velocity. The thickness of the pipe is determined by the maximum pressure the pipe should retain. For this calculation, we use Barlow's formula. ${ }^{17}$

$$
t=\frac{P d}{2(S-P)}
$$

Where $t$ is the thickness of the pipe, $S$ is the Specific yield of the material of pipe, $\mathrm{d}$ is the internal diameter of the pipe, $P$ is the maximum pressure to be retained by the pipe. As there will be head losses while transporting the $\mathrm{CO}_{2}$, booster pumps are used to maintain the pressure above the critical pressure. The spacing of these is found out by using the Darcy-Weisbach equation. Here, we assume that all the head loss is due to friction and is given by

$$
h_{f}=f \cdot \frac{L}{d} \frac{U^{2}}{2 g}
$$


Where $\mathrm{f}$ is the coefficient of friction, $\mathrm{L}$ is the length of pipe; half is $_{\text {s }}$ the head loss due to friction. By fixing the allowable head loss we can find the spacing of pumps.

\section{B. Estimation of formation site's storage capacity}

As mentioned above, though there are various sources where we can store $\mathrm{CO}_{2}$. Geological sequestration is found out to be best storage site with huge storage potential and with less risk of environmental contamination. According to Mo et al. ${ }^{10}$ the best sites for storage are:

a. Exhausted Oil and Gas reserves

b. Coal formations

c. Saline/ brine formations

Among these saline aquifers have largest storage potential and are considered to be best storage sites. The estimation of storage capacities is given below.

Oil and Gas formations: In the above three storage sites, we know the characteristics of the oil reservoir more. We assume that the volume of $\mathrm{CO}_{2}$ which can be stored in these sites is equal to or slightly less than the volume of the oil extracted. For this estimation we use the following equation: ${ }^{18}$

$$
G_{\mathrm{CO}_{2}}=A h_{n} \varphi_{e}\left(1-S_{w i}\right) B \rho_{\mathrm{CO}_{2} \text { std }} E_{\text {oil } / g a s}
$$

$\mathrm{G}_{\mathrm{CO} 2}$ is the storage resource mass estimate of carbon-di-oxide, $A$ is net surface area, $h_{n}$ is the net aquifer thickness, $\varphi_{e}$ is the effective porosity, $\left(1-S_{w i}\right)$ original hydrocarbon saturation, B is the gas or oil volume factor, $\rho_{\mathrm{CO} 2 \mathrm{std}}$ is the standard density of carbon-di-oxide, $E_{\text {oil/gas }}$ is the coefficient of efficiency of storage of reservoir.

Deep saline/brine formations: According to Bachu ${ }^{19}$ saline aquifers have the greatest storage potential among all other known types of geological storage. Not all the saline aquifers are suitable for storage. Aquifers having sufficient pressure to maintain the $\mathrm{CO}_{2}$ in either liquid or supercritical state are only suitable. Another condition is that the storage formation should have a low permeable caprock preventing $\mathrm{CO}_{2}$ to escape until the solubility mechanism comes into the picture. The capacity of the aquifer satisfying all these conditions is calculated by using this equation: ${ }^{18}$

$$
G_{\mathrm{CO}_{2}}=A h_{n} \varphi_{\text {tot }} \rho E_{\text {saline }}
$$

$\mathrm{G}_{\mathrm{CO} 2}$ is the storage resource mass estimate of carbon-di-oxide, $\mathrm{A}$ is the total gross area of formation, $h_{n}$ net aquifer thickness, $\varphi_{\text {tot }}$ is the total porosity, $\rho$-standard density of carbon-di-oxide, $E_{\text {saline }}$ is the factor indicating the efficiency of storage.

Un-economical Coal mines: Un economical or un-minable coal mines are also potential storage sites. The selection criteria for these sites are that the permeability of coal bed should be greater than 1 $\mathrm{md}$. The deeper you go the more permeability decreases. According to IPCC 2005, the depth limit for coal bed storage is around 1300-1400 $\mathrm{m}$ below the surface of the earth. The storage capacity of a coal bed can be calculated by equation (6) (Goodman et al. 2011) $)^{17}$

$$
G_{\mathrm{CO}_{2}}=A h_{n} C_{s, \max } \varphi_{\text {tot }} \rho_{\mathrm{CO}_{2}, \text { std }} E_{\text {coal }}
$$

$\mathrm{G}_{\mathrm{CO} 2}$ is the storage resource mass estimate of carbon-di-oxide, $\mathrm{A}$ is the area, $\mathrm{h}$ formation thickness, $C_{s, \max }$ is the maximum absorption capacity of carbon-di-oxide by unit volume coal bed, $\varphi_{t o t}$ is the total porosity, $\rho$-standard density of carbon-di-oxide, $E_{\text {coal }}$ is the efficiency of storage.

\section{Modeling of sink performance}

Modeling of sink performance is nothing but finding out the behavior of the carbon-dioxide after injection into the reservoir. As we don't know the exact conditions in the reservoir, we rely on numerical results. The behavior of $\mathrm{CO}_{2}$ will change with time and spatial scale. We can either use a multidimensional model having various parameters and equations for finding out the state of $\mathrm{CO}_{2}$ to give accurate values or we can use a simple model with many assumptions which are easy to compute and which gives an overall idea of $\mathrm{CO}_{2}$ in the formation. Based on the first approach, complex 3-dimensional models are generated. In these 3D models, many processes which are expected to occur inside are included and parameters which determine capillary pressure, permeability, dispersion, diffusion, equations of state, the energy of transport and geochemical reactions are also included. Although these kinds of models are accurate, due to data unavailability (and too much effort in obtaining the required data) these models are not always used. However, suitable assumptions are made to simplify these 3- dimensional models to produce results with reasonable accuracy. Some of these simplified models which are widely used are TOUGH2, ECLIPSE, LLNL, STOMP, NUFT. Among those TOUGH2 is mostly used. It assumes Darcy's law to be applicable for all the phases in the system, no chemical reactions, and all phases to be in local chemical and thermal equilibrium.

\section{Conclusion}

From the above study, the conclusions can be drawn as follows:

i. Artificial Carbon Sequestration should be focused as it is a promising technique to prevent accumulation of greenhouse gases such as $\mathrm{CO}_{2}$

ii. The potential coal beds and oil reservoirs should be identified and should be used for carbon sequestration as the additional fuel extraction might motivate industries to contribute towards the carbon sequestration.

iii. Ocean sequestration has also great potential and should be investigated more thoroughly.

iv. Geological sequestration is proved to be safe and efficient, so industries should focus on using this method instead of releasing $\mathrm{CO}_{2}$ into the atmosphere.

v. Investigations on economical carbon capture techniques are a potential research area.

\section{Acknowledgments}

None.

\section{Conflicts of interest}

Author declares there is no conflicts of interest.

\section{References}

1. Gough Clair, Paul Upham. Biomass Energy with Carbon Capture and Storage (BECCS or Bio-CCS). Greenhouse Gases: Science and Technology. 2011;1(4):324-334.

2. Socolofsky SA, Bhaumik T. Dissolution of Direct Ocean Carbon Sequestration Plumes Using an Integral Model Approach. Journal of Hydraulic Engineering. 2008;134(11):1570-1578.

3. Bachu Stefan. Sequestration of $\mathrm{CO} 2$ in geological media: criteria and approach for site selection in response to climate change. Energy Conversion and Management. 2000;41(9):953-970. 
4. Breeze Paul. Carbon Capture and Storage. Coal-Fired Generation 2015:73-86.

5. Zhang Xiangping, Xiaochun Zhang, Haifeng Dong, et al. Carbon Capture with Ionic Liquids: Overview and Progress. Energy and Environmental Science. 2012;5(5):6668-6681.

6. Bachu Stefan. $\mathrm{CO}_{2}$ storage in geological media: role, means, status and barriers to deployment. Progress in Energy and Combustion Science. 2008;34(2):254-273.

7. White CM, Strazisar BR, Granite EJ, et al. Separation and capture of $\mathrm{CO} 2$ from large stationary sources and sequestration in geological formations--coalbeds and deep saline aquifers. J Air Waste Manag Assoc. 2003;53(6):645-715

8. Bandilla Karl W, Michael A Celia, Jens T Birkholzer, et al. Multiphase Modeling of Geologic Carbon Sequestration in Saline Aquifers. Groundwater. 2015;53(3):362-377.

9. Barnes David, Robert E Froese, Mannes RG, et al. Combined Sustainable Biomass Feedstock Combustion, CO2/EOR, and Saline Reservoir Geological Carbon Sequestration in Northern Lower Michigan, USA Towards Negative CO2 Emissions. Energy Procedia. 2011;4:2955-2962.

10. Mo S, Lindeberg E, Zweigel P, et al. Effect of Geologic Parameters on $\mathrm{CO} 2$ Storage in Deep Saline Aquifers. SPE Europec/EAGE Annual Conference Madrid. 2005; 8 p.

11. Bae Youn Sang, Randall Q Snurr. Development and evaluation of porous materials for carbon dioxide separation and capture. Angewandte Chemie - International Edition. 2011;50(49):11586-11596.
12. Zhang Dongxiao, Juan Song. Mechanisms for Geological Carbon Sequestration. Procedia IUTAM. 2013;10:319-327.

13. Stefan Bachu, Gunter WD, Perkins EH. Aquifer disposal of CO2: Hydrodynamic and mineral trapping. Energy Conrers Mgmt. 1994;35(4):269-279.

14. Bolland Olva. Carbon Dioxide Capture. 2009

15. Song Juan, Dongxiao Zhang. Comprehensive Review of CaprockSealing Mechanisms for Geologic Carbon Sequestration. Environmental Science and Technology. 2013;47(1):9-22.

16. Zanotti Cristina, Paulo HR Borges, Aamer Bhutta, et al. Bond Strength between Concrete Substrate and Metakaolin Geopolymer Repair Mortar: Effect of Curing Regime and PVA Fiber Reinforcement. Cement and Concrete Composites. 2017;80:307-316.

17. Chandel MK, Gurjar BR, Ojha CSP, et al. Modeling and uncertainty analysis of transport and geological sequestration of $\mathrm{CO} 2$. Carbon Capture and Storage. 2015.

18. Goodman A, Hakala A, Bromhal G, et al. U.S. DOE Methodology for the Development of Geologic Storage Potential for Carbon Dioxide at the National and Regional Scale. International Journal of Greenhouse Gas Control. 2011;5(4):952-965.

19. Bachu Stefan. Sequestration of $\mathrm{CO}_{2}$ in geological media in response to climate change: road map for site selection using the transform of the geological space into the $\mathrm{CO}$ phase space. Energy Conversion and Management. 2002;43(1):87-102. 